\title{
Potentiation of apoptosis by histone deacetylase inhibitors and doxorubicin combination: cytoplasmic cathepsin B as a mediator of apoptosis in multiple myeloma
}

\author{
V Cheriyath", ${ }^{*, 2}$, MA Kuhns', ME Kalaycio² and EC Borden' \\ 'Translational Hematology and Oncology Research, Taussig Cancer Institute, Cleveland Clinic, Cleveland, OH 44 I95, USA; ${ }^{2}$ Department of Hematology \\ Oncology and Blood Disorders, Taussig Cancer Institute, Cleveland Clinic, Cleveland, OH 44I95, USA
}

BACKGROUND: Although inhibitors of histone deacetylase inhibitors (HDACis) in combination with genotoxins potentiate apoptosis, the role of proteases other than caspases in this process remained elusive. Therefore, we examined the potentiation of apoptosis and related mechanisms of HDACis and doxorubicin combination in a panel of myeloma cell lines and in 25 primary myelomas.

RESULTS: At $I_{50}$ concentrations, sodium butyrate (an HDACi) or doxorubicin alone caused little apoptosis. However, their combination potentiated apoptosis and synergistically reduced the viability of myeloma cells independent of p53 and caspase 3-7 activation. Potentiated apoptosis correlated with nuclear translocation of apoptosis-inducing factor, suggesting the induction of caspase 3- and 7-independent pathways. Consistent with this, butyrate and doxorubicin combination significantly increased the activity of cytoplasmic cathepsin B. Inhibition of cathepsin B either with a small-molecule inhibitor or downregulation with a siRNA reversed butyrate- and doxorubicin-potentiated apoptosis. Finally, ex vivo, clinically relevant concentrations of butyrate or SAHA (suberoylanilide hydroxamic acid, vorinostat, an HDACi in clinical testing) in combination with doxorubicin significantly $(P<0.000 \mathrm{I}$ ) reduced the survival of primary myeloma cells.

CONCLUSIONS: Cathepsin B has a prominent function in mediating apoptosis potentiated by HDACi and doxorubicin combinations in myeloma. Our results support a molecular model of lysosomal-mitochondrial crosstalk in HDACi-and doxorubicin-potentiated apoptosis through the activation of cathepsin B.

British Journal of Cancer (201 I) 104,957-967. doi:10.1038/bjc.2011.42 www.bjcancer.com

Published online I March 201 |

(c) 201I Cancer Research UK

Keywords: HDAC inhibitors; cathepsin B; doxorubicin; apoptosis and multiple myeloma

Despite recent advances, disease recurrence and side effect profiles of existing drugs remain a problem in multiple myeloma (Ludwig et al, 2010; Niesvizky and Badros, 2010; Richards and Weber, 2010). As evasion of apoptosis may be important for early expansion and accumulation of mutant plasma cells, identification of drug combinations that potentiate apoptosis might be beneficial for achieving better outcomes (Bergsagel and Kuehl, 2001; Cheriyath et al, 2007b).

Besides caspases, proteolysis is mediated by lysosomal cathepsins such as cathepsin B and cathepsin D in apoptosis (Boya et al, 2003; Broker et al, 2004; Paquet et al, 2005; He et al, 2005a; Turk and Stoka, 2007). Once released from lysosomes, cathepsins may contribute to apoptosis execution either by direct cleavage of cellular substrates, by acting in concert with caspases or by disrupting the mitochondrial transmembrane potential $(\Delta \Psi)$ (Boya et al, 2003; Broker et al, 2004; Paquet et al, 2005; He et al, 2005a; Turk and Stoka, 2007). Various insults including oxidative stress and DNA damage may lead to the limited release of cathepsins that culminate in the induction of apoptosis. However,

*Correspondence: Dr V Cheriyath; E-mail: cheriyv@ccf.org Revised 28 October 2010; accepted 24 January 201 I; published online I March 2011 the release of cathepsin in excess may lead to cellular necrosis (Paquet et al, 2005).

Cancer cells evade apoptosis by both genetic (mutations) and epigenetic means (Egger et al, 2004). Perturbation of the balance between histone acetyltransferases and histone deacetylases (HDACs) has been defined in myeloma and in other cancers (Mitsiades et al, 2003; Marks and Xu, 2009; Luszczek et al, 2010). Consequently, inhibition of HDACs has emerged as a potential therapeutic strategy (Glaser, 2007; Richon et al, 2009). Histone deacetylase inhibitors (HDACis) include several classes, ranging from the simple aliphatic acid sodium butyrate (butyrate) to more complex hydroxamic acid-derived compounds, such as SAHA (suberoylanilide hydroxamic acid, vorinostat; Moradei et al, 2008; Balliet et al, 2009). Histone deacetylase inhibitors cause cytotoxicity of cancer cells epigenetically by re-expressing silenced tumour suppressors (Laird, 2005; Glaser, 2007; Richon et al, 2009) or by altering acetylation status of cellular proteins through nonepigenomic mechanisms (Pei et al, 2004; Dai et al, 2005; Chen et al, 2007).

Toxicities associated with cumulative or higher dosages limit HDACi usage as a monotherapy (Richardson et al, 2008; Badros et al, 2009; Richon et al, 2009). To overcome this limitation, synergistic interaction of HDACi with a variety of anticancer agents including anthracyclins, which inhibits topoisomerases I 
and II, have been explored (Marchion et al, 2004; Mitsiades et al, 2004; Catalano et al, 2006; Pan et al, 2007; Hajji et al, 2008; Sanchez et al, 2010). In myeloma cell lines, at above $\mathrm{IC}_{50}$ concentrations, HDACi (SAHA and LBH589) and anthracyclins potentiate apoptosis through a variety of mechanisms, including the induction of caspase 3 and 7 or by altering the expression of proapoptotic genes (Mitsiades et al, 2004; Sanchez et al, 2010). However, the molecular mechanisms of the synergy between $\mathrm{HDACi}$ and doxorubicin at their $\mathrm{IC}_{50}$ or sub- $\mathrm{IC}_{50}$ concentrations are not known. In this study, we identified a critical role for cathepsin $\mathrm{B}$ in mediating the potentiation of apoptosis in myeloma cells by $\mathrm{HDACi}$ and doxorubicin combinations at their $\mathrm{IC}_{50}$ concentrations. Moreover, both experimental (butyrate) and a clinically relevant HDACi (vorinostat) and liposomal doxorubicin (doxil) significantly reduced the viability of patient-derived primary myeloma cells, providing a rationale of combining this non-neurotoxic and steroid sparing combination for myeloma and other haematological malignancies.

\section{MATERIALS AND METHODS}

\section{Cell lines}

Human multiple myeloma cell lines RPMI 8226, U266 and NCI-H929 were purchased from the ATCC (Manassas, VA, USA); KMS-11 and OPM-2 cells were kind gifts from Drs Taolin Yi and Eric Hsi of the Cleveland Clinic. All cells were propagated in recommended media.

\section{Reagents and antibodies}

Sodium butyrate was purchased from Sigma (Sigma-Aldrich, St Louis, MO, USA), SAHA (vorinostat) was provided by Merck \& Co. Inc., (Whitehouse Station, NJ, USA) and liposomal doxorubicin (Doxil) was obtained from the Cleveland Clinic Cancer Pharmacy. Cathepsin B inhibitor CA-074Me was obtained from Calbiochem (Calbiochem Inc., San Diego, CA, USA) and caspase 3 inhibitor DEVD-CHO and pan-caspase inhibitor z-VADFMK were from BioMol Inc., (Plymouth Meeting, PA, USA). Antibodies for caspase 3 and apoptosis-inducing factor (AIF) were from Cell Signaling Technology Inc., (Danvers, MA, USA). Cathepsin B antibody was from Sigma (Sigma-Aldrich). Cathepsin stealth siRNA was from Invitrogen Inc (Carlsbad, CA, USA).

\section{Viability assays and synergy analysis}

Human multiple myeloma cell lines were seeded in 96-well plates at a concentration of $5 \times 10^{3}$ cells per well and incubated for $72 \mathrm{~h}$ with various concentrations of butyrate, doxorubicin or their combinations. At the end of incubation, the percentage reduction in cell viability compared with untreated cells was determined with Alamar blue (Invitrogen Inc.) as described (Cheriyath et al, 2007a). The median drug effect for butyrate, doxorubicin and their combinations was analysed using Calcusyn software (Chou and Talalay analysis) to derive the combination indices.

Informed consent for bone marrow (BM) aspirates was obtained in accordance with protocols approved by the Institutional Review Board of Cleveland Clinic (Cleveland, OH, USA). The effect of HDACi, doxorubicin or their combinations on the survival of fresh myeloma cells after drug treatments was measured as previously described (Lincz et al, 2001; Cheriyath et al, 2007a).

\section{Apoptosis and caspase 3 and 7 activity assay}

TUNEL labelling (BD Biosciences, San Jose, CA, USA) and caspase 3 and 7 activities (Caspase-Glo assay reagent, Promega Inc., Madison, WI, USA) were measured according to manufacturer's instructions and as described (Cheriyath et al, 2007a; Bae et al, 2008).

\section{Cathepsin B, cathepsin D and calpain assays}

Cathepsin B, cathepsin D and calpain activity kits were used to measure enzymatic activity according to manufacturer's instructions (Biovision Inc., Mountain View, CA, USA). Briefly, $1 \times 10^{6}$ cells were treated with butyrate, doxorubicin or their combination for the indicated time periods. Cytoplasmic cathepsin B activity was assessed in cytoplasmic extracts prepared by permeabilising the plasma membrane with digitonin containing buffer $\left(50 \mu \mathrm{g} \mathrm{ml}^{-1}\right.$ digitonin, $250 \mathrm{~mm}$ Sucrose, $20 \mathrm{~mm}$ Hepes, $10 \mathrm{~mm} \mathrm{KCl,} 1.5 \mathrm{~mm} \mathrm{MgCl}$, 1 mM EDTA, 1 mM EGTA, 1 mm Pefablock, pH 7.5) for 10 min on ice. A measure of $15 \mu \mathrm{l}$ of cytoplasmic extract was then diluted with $35 \mu \mathrm{l}$ of assay buffer and incubated with AFP-conjugated substrates for $1 \mathrm{~h}$. The increase in fluorescence was measured with a Wallac Victor2 fluorimeter (Waltham, MA, USA). Lactate dehydrogenase (LDH) activity using cytotox 96 well assay kit (Promega Inc.) was used to monitor permeabilisation of plasma membrane and to normalise the activity of cytoplasmic cathepsin B.

\section{Indirect immunofluorescence microscopy}

Cells left untreated or treated with butyrate, doxorubicin or their combination for the indicated time periods were cytospun and fixed with $4 \%$ paraformaldehyde for $10 \mathrm{~min}$. Fixed cells were permeabilised with $0.2 \%$ Triton $\mathrm{X}-100$ for $10 \mathrm{~min}$ and incubated with monoclonal anti-AIF antibody (dilution of $1: 200$ ) for $1 \mathrm{~h}$ followed by secondary antibody conjugated with Alexa-488 (dilution $1: 1000$; Invitrogen Inc.). Cells were then mounted with Prolong Gold mounting media with DAPI and imaged using a Leica DMI4000B fluorescence microscope (Leica, Bannockburn, IL, USA).

\section{Immunoblot analysis}

Whole-cell extracts (WCE) were made by lysing $1 \times 10^{6}$ cells with RIPA buffer (Sigma-Aldrich) containing $1 \times$ protease inhibitor cocktail (Calbiochem). A quantity of $25-35 \mu \mathrm{g}$ of WCE was subjected to immunoblot analysis as previously described (Cheriyath et al, 2007a; Bae et al, 2008).

\section{siRNA-mediated downregulation of cathepsin B}

Cells $\left(1 \times 10^{6}\right)$ were transfected with cathepsin B stealth siRNA by Lipofectin according to manufacturer's instructions (Invitrogen Inc.). After $24 \mathrm{~h}$ transfection, cells were treated with butyrate, doxorubicin or their combination for $72 \mathrm{~h}$.

\section{Statistical analysis}

One-way repeated measures ANOVA followed by all pairwise multiple comparison procedures (Holmes-Sidak method) were performed using SigmaStat 3.5 software to determine the significance of difference between untreated, single agent and combination-treated fresh myeloma samples. One-way ANOVA followed by Tukey's Multiple Comparison Test was used to determine the significance of difference of cathepsin B activity and potentiation of apoptosis between the untreated and treated samples. Two-tailed $t$-test was used to determine the significance of difference of the effects of caspase 3 and cathepsin B inhibitors on apoptosis.

\section{RESULTS}

\section{HDACi and doxorubicin combination potentiated apoptosis in myeloma cells}

To assess whether the combination of butyrate and doxorubicin potentiate apoptosis at their $\mathrm{IC}_{50}$ or sub- $\mathrm{IC}_{50}$ concentrations, five myeloma cell lines carrying wild-type or mutant p53 alleles were 
treated with either butyrate, doxorubicin alone or with their combination for $48 \mathrm{~h}$, and apoptotic indices were assessed by TUNEL assay (Figure 1A). In initial studies, the $\mathrm{IC}_{50}$ of butyrate, SAHA and doxorubicin were determined in NCI H929, RPMI 8226 and U266 cells (Supplementary Figure 1 and Supplementary Table 1). Butyrate or doxorubicin alone had only a modest effect on TUNEL positivity. However, their combination markedly increased TUNEL staining in all myeloma cell lines tested irrespective of p53 status (Figure 1A). An exception to this was OPM2 cells, in which doxorubicin alone resulted in $54.7 \%$ positive TUNEL staining (Figure 1A). These results suggested that potentiation of apoptosis by the combination may lead to synergistic reduction in the viability of myeloma cells.

As augmented inhibition of HDACs could lead to potentiation of apoptosis, effects of butyrate, doxorubicin and their combination on HDAC activity was tested by assessing histone-H4 acetylation. As expected, butyrate induced the acetylation of histone H4 in RPMI 8226 and NCI-H929, indicating the inhibition of HDACs (Figure 1B). However, acetylation status of histone $\mathrm{H} 4$ was unaltered by doxorubicin alone or in combination with butyrate (Figure 1B). These results suggest that potentiated apoptosis by the combination is not resulting in from the augmented inhibition of HDACs.

In agreement with the potentiated apoptosis, combinations of HDACi and doxorubicin synergistically reduced viability of myeloma cell lines (Supplementary Figure 2). Compared with single agents, butyrate $(150,300$ and $600 \mu \mathrm{M})$ and doxorubicin $(15,30$ and $60 \mathrm{~nm})$ co-treatment with incrementally increased concentrations markedly reduced the viability of myeloma cells. In all three cell lines, butyrate and doxorubicin combinations resulted in a combination index of $<1$ in Chou and Talalay analysis, indicating synergistic interaction between them (Supplementary Figure $2 \mathrm{~A}$ ). To understand the relative contribution of HDACi to the synergy, myeloma cells were treated with a fixed concentration of doxorubicin ( $40 \mathrm{~nm}$ ) and varying concentrations of butyrate $(0-800 \mu \mathrm{M})$. Similar to incrementally increased concentrations of butyrate and doxorubicin, increased concentrations of butyrate with a constant concentration of doxorubicin also resulted in synergy with a combination index of $<1$ (Supplementary Figure 2B). As in co-treatment, sequential treatment (SAHA followed by doxorubicin) also synergistically reduced the viability of myeloma cell lines (data not shown).

\section{HDACi and doxorubicin significantly reduced viability of patient-derived fresh myeloma cells}

To define the clinical relevance of HDACi and doxorubicin combination, the antimyeloma activity of the clinically relevant concentrations of HDACi and doxorubicin combinations was tested in patient-derived primary myeloma cells $(n=25)$. Characteristics of the patients and treatments that they received before the collection of BM aspirates are provided (Supplementary Table 2). $\mathrm{CD}_{138^{+}}$cells derived from BM aspirates of 18 myeloma patients were left untreated or treated with butyrate, doxorubicin or their combination in the presence of BM mononuclear cells, which includes stromal cells. After $72 \mathrm{~h}$ of treatment, survival of $\mathrm{CD}_{138}{ }^{+}$cells was assessed by flow cytometry. Compared with untreated cells, butyrate $(600 \mu \mathrm{M})$ or doxorubicin (40 nM) alone had only a marginal effect on the survival of $\mathrm{CD} 138^{+}$cells (100\% untreated vs $72.97 \%$ butyrate and $83.25 \%$ doxorubicin treated; Table 1). However, co-treatment of butyrate and doxorubicin significantly reduced the survival of $\mathrm{CD}_{138^{+}}$cells $(43.42 \%, P \leqslant 0.05$; Table 1$)$. While butyrate $(600 \mu \mathrm{M})$ and doxorubicin $(40 \mathrm{nM})$ reached $\mathrm{IC}_{50}$ in 4 out of 18 and 1 out of 18 patient samples, respectively, their combination reached $\mathrm{IC}_{50}$ in 10 out of 18 patient samples.

Effect of combinations of HDACi and doxorubicin on the survival of fresh myeloma cells was further investigated using
SAHA in BM aspirates from 12 myeloma patients. In initial studies, the $\mathrm{IC}_{50}$ of SAHA for myeloma cell lines ranged from 546 to $976 \mathrm{nM}$ (Supplementary Table 1). Compared with single agents, combination of SAHA (200 $\mathrm{nM})$ and doxorubicin ( $40 \mathrm{nM})$ markedly reduced viability of fresh myeloma cells. At the concentrations used, neither SAHA nor doxorubicin reached $\mathrm{IC}_{50}$ or $\mathrm{IC}_{25}$, but, combining SAHA with doxorubicin reached $\mathrm{IC}_{50}$ in 5 out of the 12 samples and $\mathrm{IC}_{25}$ in 11 out of the 12 samples (Table 1 ). In oneway repeated measures of ANOVA, the sub- $\mathrm{IC}_{50}$ concentration of SAHA used had only a marginal effect on the survival of fresh myeloma cells $\left(\mathrm{CD} 38^{+} ; 80.87 \%\right.$ in SAHA treated vs $100 \%$ in untreated). However, combining SAHA with doxorubicin significantly reduced the survival of fresh myeloma cells to $46.29 \%$ $(P \leqslant 0.05$; Table 1$)$.

\section{HDACi- and doxorubicin-potentiated apoptosis was caspase 3 and 7 independent}

To gain a better understanding of the mechanism of apoptosis potentiated by butyrate and doxorubicin, effects of these agents alone or in combination on caspase-dependent and -independent apoptosis were investigated. Butyrate and doxorubicin treatments had no marked effect on the activity of caspase 3 and 7 in NCI H929, RPMI 8226 and U266 cell lines at $24 \mathrm{~h}$ (Figure 2A). Under the same conditions TRAIL, a potent inducer of apoptosis, markedly increased the activity of caspase 3 and 7 in sensitive cell lines (NCI H929 and RPMI 8226), suggesting the absence of an intrinsic block in caspase activation pathways in these cell lines. Lack of caspase 3 activation was confirmed by caspase 3 cleavage assay at 16,24 and $36 \mathrm{~h}$ (Figure 2B). The role of caspase 3 in apoptosis potentiated by butyrate and doxorubicin was further tested by pretreating RPMI 8226 cells with DEVD-CHO, a cell permeable caspase 3-specific peptide inhibitor. DEVD-CHO inhibited the activity of caspase 3 and 7 (Figure 2C). Consistent with its inhibition of caspase activity, DEVD-CHO significantly reduced the apoptosis induced by TRAIL from 41.4 to $19.5 \%(P=0.0065)$; however, it had no apparent effect on apoptosis potentiated by the butyrate and doxorubicin combination (Figures 2C and D). Influence of caspases other than caspase 3 and 7 on butyrate and doxorubicin combination potentiated apoptosis was tested using z-VAD-FMK, a pan-caspase inhibitor. Compared with vehicle-treated cells, $\sim 12 \%$ decrease in apoptosis was observed in z-VAD-FMK-treated cells (Supplementary Figure 3). Together, these results suggest the involvement of caspases other than 3 and 7 in the potentiation of apoptosis by HDACi and doxorubicin.

As apoptosis potentiated by butyrate and doxorubicin was not caspase 3 and 7 dependent, nuclear translocation of AIF, a mediator of caspase-independent apoptosis, was assessed in RPMI 8226 and NCI H929 cells using indirect immunofluorescence microscopy. In untreated, butyrate- or doxorubicin-treated RPMI 8226 and NCI H929 cells, most of the AIF was localised in mitochondria resulting in very little colocalisation of AIF with nuclear stain DAPI (Figure 2E). However, the combination of butyrate and doxorubicin markedly increased the nuclear translocation of AIF in both RPMI 8226 and NCI H929 cells (Figure 2E). These results together with the lack of caspase 3 and 7 activation suggested the involvement of caspase 3- and 7-independent pathways in mediating the apoptosis potentiated by HDACi and doxorubicin combinations.

\section{HDACi and doxorubicin significantly increased the activity of cytoplasmic cathepsin B}

On the basis of the role of cathepsin B in mediating AIF activation and apoptosis induced by agents that act on DNA (Bidere et al, 2003; Broker et al, 2004; Biswas et al, 2005), we postulated that increased activity of cathepsin B in the cytoplasm may be a critical mediator of HDACi and doxorubicin combination induced 

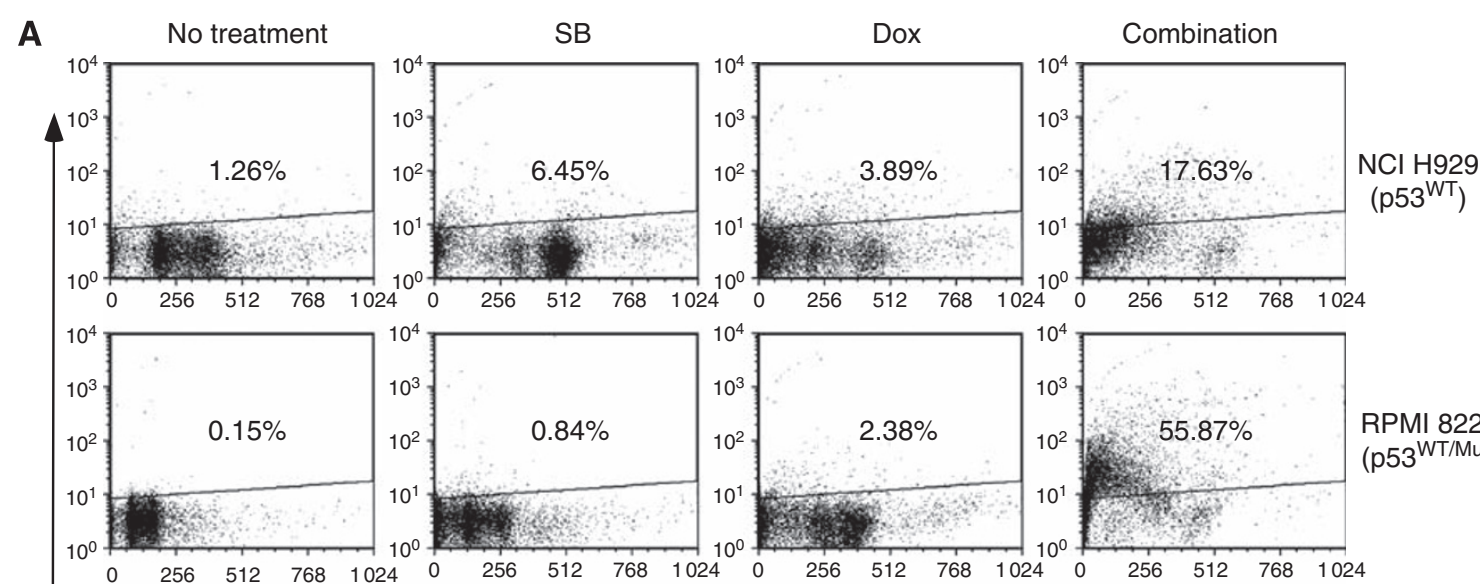

RPMI 8226

(p53 $3^{\text {WT/Mut }}$
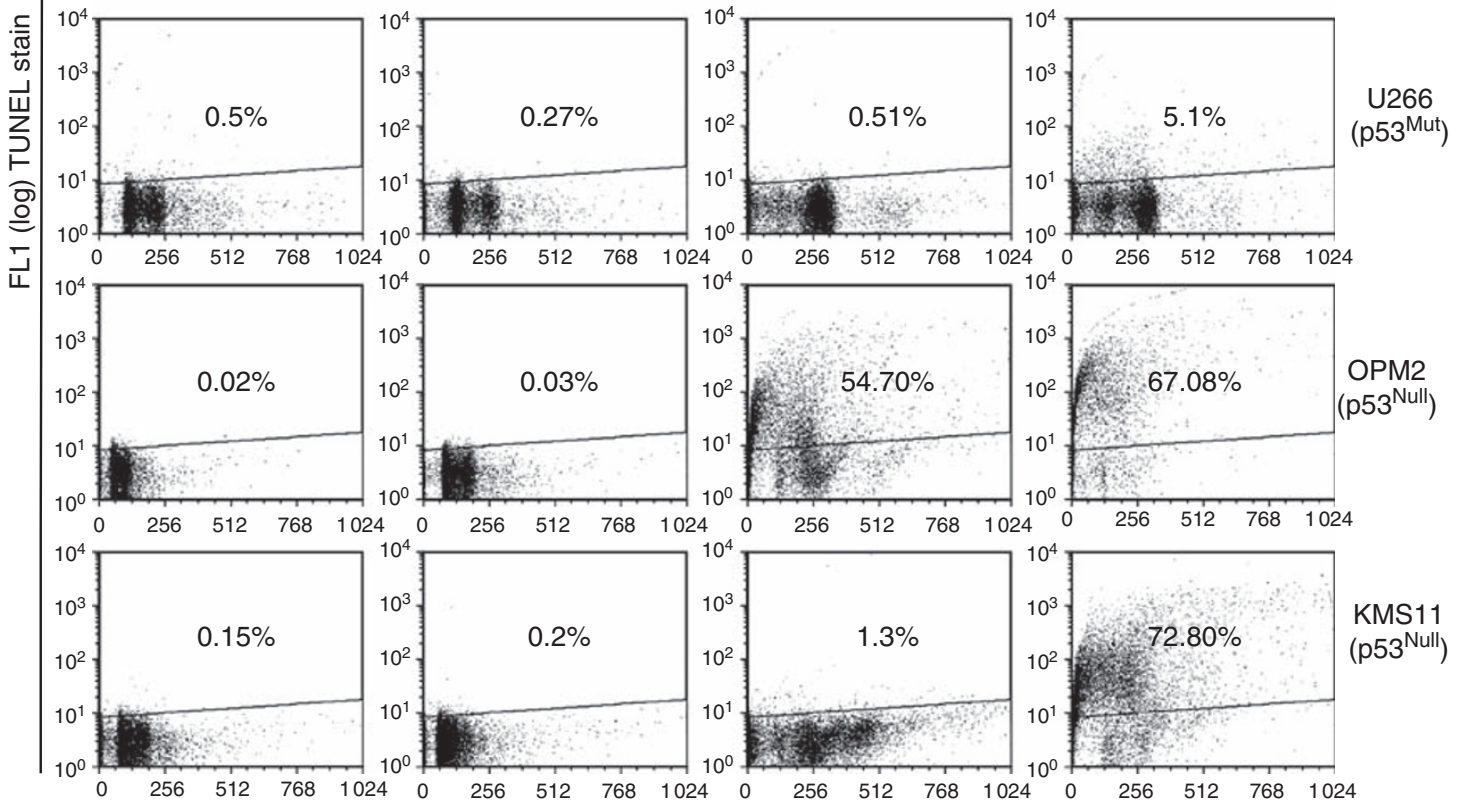

FL3 (Lin) P.

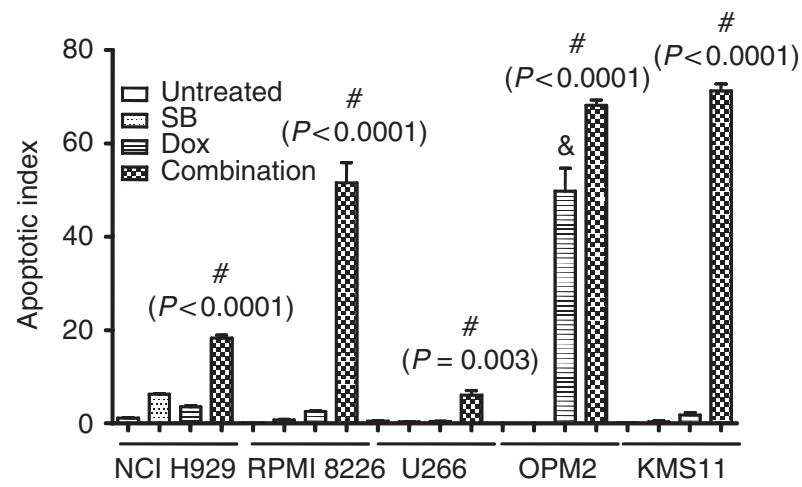

B

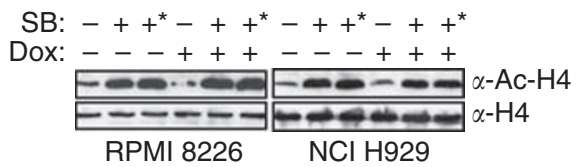

Figure I Combinations of HDACi and doxorubicin potentiate apoptosis in myeloma cells. (A) Effects of HDACi, doxorubicin and their combination on apoptosis of myeloma cells with varying p53 status. Myeloma cells $\left(\mathrm{I} \times 10^{6}\right)$ carrying either wild-type or mutant p53 ( NCI H929, RPMI 8226, U266, KMSI I and OPM2) were left untreated or treated with butyrate (300 $\mu \mathrm{M}$ for NCl H929 and $600 \mu \mathrm{M}$ for RPMI 8226, U266, KMS II and OPM2) or doxorubicin ( $40 \mathrm{nM}$ ) or with their combination for $48 \mathrm{~h}$. Percentage of cells undergoing apoptosis was assessed by TUNEL staining. Scatter plot shown is a representative of two independent experiments with similar results, in which 10000 events were collected using flow cytometry. Mutational status of p53 of the myeloma cell lines is indicated. Induction of apoptosis in myeloma cells by butyrate, doxorubicin and their combination are summarised in the bottom graph. Each bar on the graph is mean \pm s.e.m. of two independent experiments. \# Indicates that the treatment is significantly different from other treatments and ' $\&$ ' sign indicates that treatment is significantly different from untreated or butyrate treatment; $P$-values for each treatment is provided. (B) Effect of butyrate and doxorubicin (40 nM) combination on HDAC activity. Whole-cell lysates (WHL; $30 \mu \mathrm{g}$ ) of NCl-H929 or RPMI 8226 cells left untreated or treated with butyrate $\left(+=300 \mu \mathrm{M},+^{*}=600 \mu \mathrm{M}\right)$ doxorubicin or their combination for $36 \mathrm{~h}$ and acetylation status of histone $\mathrm{H} 4$ as an indirect measure of HDAC activity was determined by immunoblot analysis. 
Table I Effects of HDACi (butyrate or SAHA) and doxorubicin or their combinations on the survival of fresh myeloma cells

$\%$ Survival of CDI $38^{+}$cells (treatments)

\begin{tabular}{|c|c|c|c|c|c|c|c|c|}
\hline Sample no. & Untreated & SB & Dox & Combo & Untreated & SAHA & Dox & Combo \\
\hline POI & 100 & 65.6 & 92.6 & 51.1 & - & - & - & - \\
\hline P02 & 100 & 71.6 & 78.2 & 1.0 & - & - & - & - \\
\hline P03 & 100 & 70.1 & 76.9 & 37.8 & - & - & - & - \\
\hline P04 & 100 & 107.7 & | 13.7 & 62.5 & - & - & - & - \\
\hline P05 & 100 & 33.9 & 85.3 & 18.9 & - & - & - & - \\
\hline P06 & 100 & 61.9 & 81.7 & 62.0 & - & - & - & - \\
\hline P07 & 100 & 104.3 & 93.3 & 85.7 & - & - & - & - \\
\hline P08 & 100 & 80.7 & 95.2 & 76.7 & - & - & - & - \\
\hline P09 & 100 & 102.2 & 101.5 & 92.7 & 100 & 85.7 & 97.8 & 88.1 \\
\hline PIO & 100 & 91.5 & 78.5 & 29.4 & 100 & 91.0 & 79.5 & 31.7 \\
\hline$P \mid I$ & 100 & 59.5 & 65.5 & 52.5 & - & - & - & - \\
\hline $\mathrm{PI} 2$ & 100 & 94.1 & 74.5 & 27.5 & - & - & - & - \\
\hline $\mathrm{P} 13$ & 100 & 39.1 & 85.8 & 19.4 & - & - & - & - \\
\hline $\mathrm{P} \mid 4$ & 100 & 85.9 & 18.9 & 7.8 & 100 & 102.5 & 19.9 & 16.0 \\
\hline PI5 & 100 & 43.9 & 74.2 & 20.5 & - & - & - & - \\
\hline PI6 & 100 & 107.3 & $1 \mid 2.5$ & 65.4 & 100 & 97.3 & | 10.5 & 60.4 \\
\hline $\mathrm{PI} 7$ & 100 & 60.6 & 73.3 & 47.7 & - & - & - & - \\
\hline PI8 & 100 & 32.9 & 96.7 & 23.0 & 100 & 79.8 & 99.5 & 67.7 \\
\hline PI9 & - & - & - & - & 100 & 83.2 & 87.8 & 73.1 \\
\hline P20 & - & - & - & - & 100 & 54.4 & 64.7 & 3.9 \\
\hline P2I & - & - & - & - & 100 & 88.3 & 101.3 & 56.2 \\
\hline P22 & - & - & - & - & 100 & 69.8 & 107.1 & 55.3 \\
\hline P23 & - & - & - & - & 100 & 41.3 & 87.5 & 16.5 \\
\hline P24 & - & - & - & - & 100 & 86.8 & 122.1 & 30.3 \\
\hline P25 & - & - & - & - & 100 & 81.4 & 92.9 & 51.4 \\
\hline Mean & 100 & $72.9^{\#}$ & $83.25^{\#}$ & $43.42 * * *$ & 100 & $80.87^{\#}$ & 89.73 & $46.29 * * *$ \\
\hline s.e.m. & 0.00 & 5.96 & 4.93 & 6.35 & 0.00 & 5.40 & 7.78 & 7.57 \\
\hline
\end{tabular}

Abbreviations: Dox = doxorubicin; HDACi = histone deacetylase inhibitor; SAHA = suberoylanilide hydroxamic acid; $\mathrm{SB}=$ sodium butyrate. Mononuclear $\left(\mathrm{I} \times 10^{5}\right)$ cells from bone marrow aspirates of patients were left untreated or treated with butyrate (600 $\mu \mathrm{M})$, SAHA (200 nM), doxorubicin (40 nM), butyrate plus doxorubicin or SAHA plus doxorubicin for $24 \mathrm{~h}$. Percentages of dead and CDI38+ positive cells were determined by flow cytometry, in which 10000 events were collected for each treatment. Statistical significance between each treatment was determined by one-way repeated analysis of variance adjusted for multiple comparisons (Holm-Sidak method). \# Significantly different from untreated and combination treated, $P<0.0001$; **** significantly different from untreated and single-agent-treated samples, $P<0.000$ I.

apoptosis. To test this hypothesis, activity of cathepsin B in cytoplasmic extracts of untreated and treated RPMI 8226 cells was determined. Permeabilisation of cells with digitonin was monitored by measuring the activity of cytoplasmic enzyme LDH (Foghsgaard et al, 2002). Incubation of cells in cytoplasmic extraction buffer with $50 \mu \mathrm{g}$ of digitonin resulted in the maximal release of $\mathrm{LDH}$ with minimal increase in the activity of cathepsin B, indicating the permeabilisation of the plasma membrane, but not lysosomes (Figure 3A). In kinetic studies compared with untreated and single agents, the combination of butyrate and doxorubicin significantly increased the cytoplasmic activity of cathepsin B at $16 \mathrm{~h}$ in RPMI 8226 cells (Figure 3B). An increase in the activity of cytoplasmic cathepsin B was also observed in NCI H929 cells treated with butyrate and doxorubicin combination (data not shown).

As other lysosomal enzymes, including cathepsin D and calpain, are also suggested to be involved in HDACi and stress-induced apoptosis, combination-mediated activation of cathepsin D and calpains was assessed in RPMI 8226 cells (Mandic et al, 2002; Carew et al, 2007). Unlike cathepsin B, butyrate and doxorubicin combination failed in activating cathepsin $\mathrm{D}$ and calpain (Figures $3 \mathrm{C}$ and $\mathrm{D})$.

\section{Cathepsin B inhibition reverses HDACi and doxorubicin combination potentiated apoptosis}

As butyrate and doxorubicin combination markedly increased the activity of cytoplasmic cathepsin B, its role in potentiating apoptosis was further investigated in RPMI 8226 cells with CA-074me, a membrane-permeable cathepsin B inhibitor
(Ostenfeld et al, 2005; Sandes et al, 2007; Wang et al, 2008). As expected, pretreatment of RPMI 8226 cells with CA-074me markedly inhibited total cathepsin B activity in control, butyrate, doxorubicin and combination treated cells (Figure 4A). Additionally, inhibition of cathepsin B activity with CA-074me significantly reduced the TUNEL positivity of RPMI 8226 cells treated with the combination from 46.84 to $17.24 \%(P=0.0009)$, suggesting a prominent role for cathepsin $B$ in the mediation of butyrate- and doxorubicin-potentiated apoptosis (Figure 4B).

To test the direct role of cathepsin $\mathrm{B}$ in mediating the HDACiand doxorubicin-potentiated apoptosis, its expression was downregulated in RPMI 8226 cells with a siRNA (Figure 4C). Compared with control siRNA-transfected cells, downregulation of cathepsin $\mathrm{B}$ reduced the butyrate and doxorubicin combination induced from 36.73 to $11.31 \%$ (Figure 4D). These results are in agreement with the results of using cathepsin B inhibitor CA-074me and confirm the role of cathepsin $\mathrm{B}$ in mediating the potentiation of apoptosis by butyrate and doxorubicin.

\section{DISCUSSION}

To further the current successes in myeloma therapy, there is a need to identify drug combinations that synergistically reduce viability of myeloma cells (Mitsiades et al, 2007; Richardson et al, 2007; Cheriyath et al, 2007b). Although anthracyclins (doxorubicin) have been used clinically as single agents or in combination to therapeutic advantage, greater effectiveness could improve activity. Moreover, the success of combination therapies could be improved by defining molecular mechanisms responsible for their antitumour 


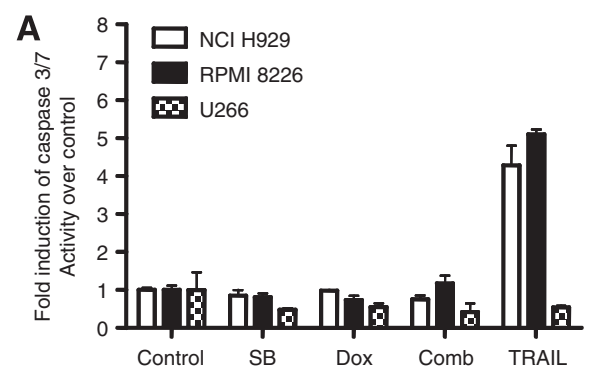

B
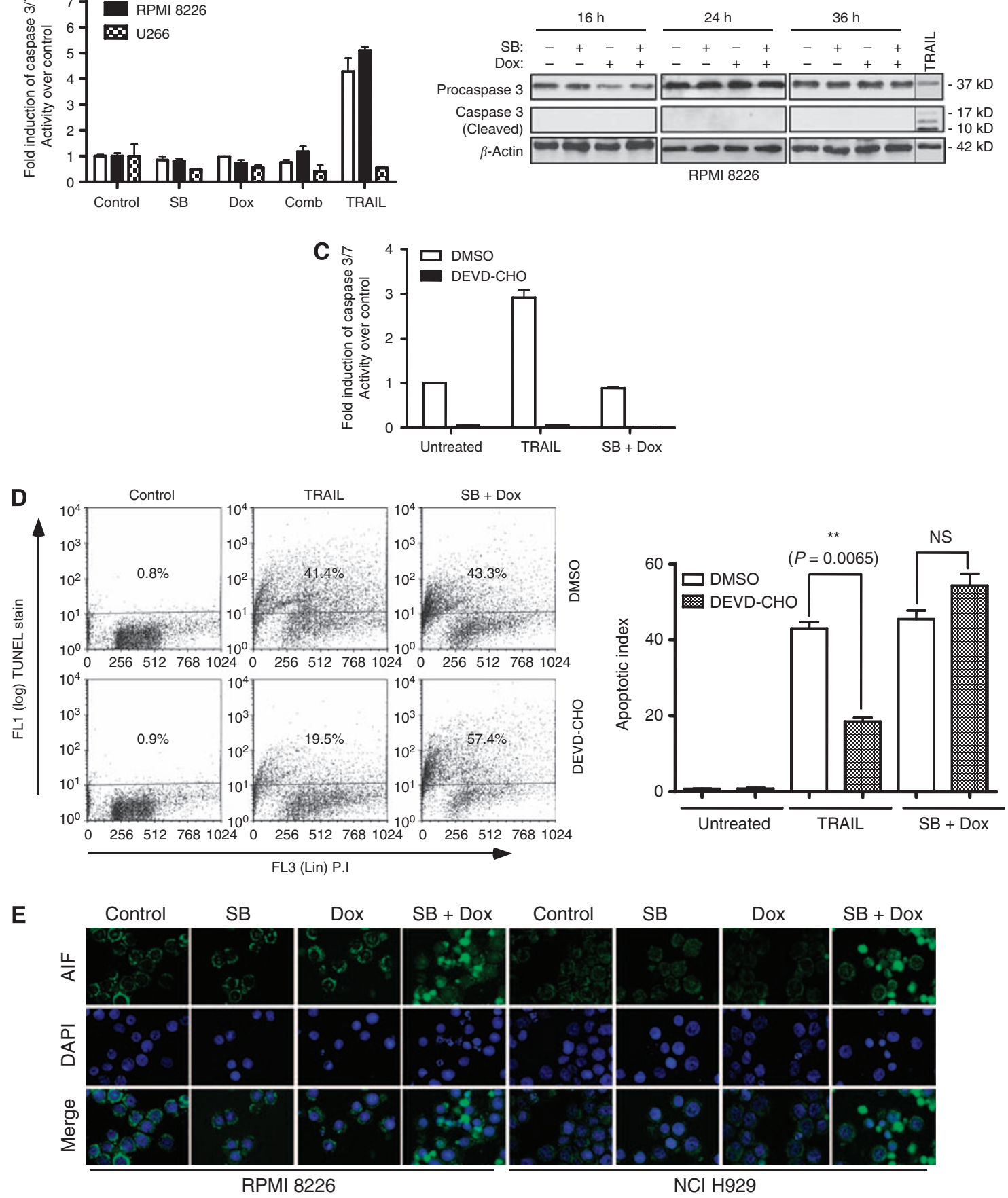

Figure 2 Effects of butyrate, doxorubicin or their combination on caspase 3 and 7 activation and AlF release in myeloma cells. (A, B) Effects of butyrate, doxorubicin and their combination on caspase 3 and 7 activation. (A) NCl H929, RPMI 8226 and U266 cells were treated with butyrate (SB; $300 \mu \mathrm{M}$ for NCl H929 and $600 \mu \mathrm{M}$ for RPMI 8226 and U266), doxorubicin (Dox; $40 \mathrm{nM}$ ) or with their combination. After $24 \mathrm{~h}$ treatments, fold change in caspase 3 and 7 activity relative to untreated cells was assessed by caspase 3 and 7 glo kit (Promega Inc.). TRAIL ( $50 \mathrm{ng} \mathrm{ml}^{-1}$, Peprotech Inc., Rocky Hill, NJ, USA) was used as a positive control. Each data point in the bar graph is mean \pm s.e.m. of three independent experiments performed in triplicate. (B) Caspase 3 cleavage was assessed after 16, 24 or $36 \mathrm{~h}$ by subjecting $30 \mu \mathrm{g}$ of whole-cell lysates (WCL) of RPMI 8226 cells to immunoblot analysis with a caspase 3-specific antibody. TRAIL-treated sample was used as a positive control and $\beta$-Actin as a loading control. (C, D) Effects of caspase 3 inhibitor DEVD-CHO on butyrate- and doxorubicin-induced apoptosis of myeloma cells. RPMI 8226 cells $\left(I \times 10^{6}\right)$ were pretreated with either vehicle (DMSO) or I $\mu$ M of cell permeable caspase 3-specific inhibitor DEVD-CHO (Biomol Inc.) for $2 \mathrm{~h}$. Then the cells were left untreated or treated with TRAlL $\left(50 \mathrm{ng} \mathrm{ml}^{-1}\right)$ or butyrate $(600 \mu \mathrm{M})$ plus doxorubicin ( $40 \mathrm{~nm}$ ). Caspase 3 and 7 activity was determined as in Figure 3A, and percentage of cells undergoing apoptosis was determined $48 \mathrm{~h}$ posttreatment by TUNEL assay as in Figure 2. Scatter plot shown is one of two independent experiments with similar results, in which 10000 events were collected (top panel). Each bar on the graph is mean \pm s.e.m. of two independent experiments, and $P$-values of significantly different treatments are provided. (E) Butyrate plus doxorubicin combination results in nuclear translocation of AIF in RPMl 8226 and NCl H929 cells. RPMI 8226 or NCl H929 cells were left untreated or treated with indicated concentrations of butyrate, doxorubicin or their combination for $48 \mathrm{~h}$. The localisation of AlF was assessed by indirect immunofluorescence staining with an AIF antibody followed by Alexa Flour-488-conjugated secondary antibody (Green staining). Nuclei of the cells were stained with DAPI (blue). Merged images were produced by superimposing both images. Results shown are representative of three independent experiments with similar results. 
A
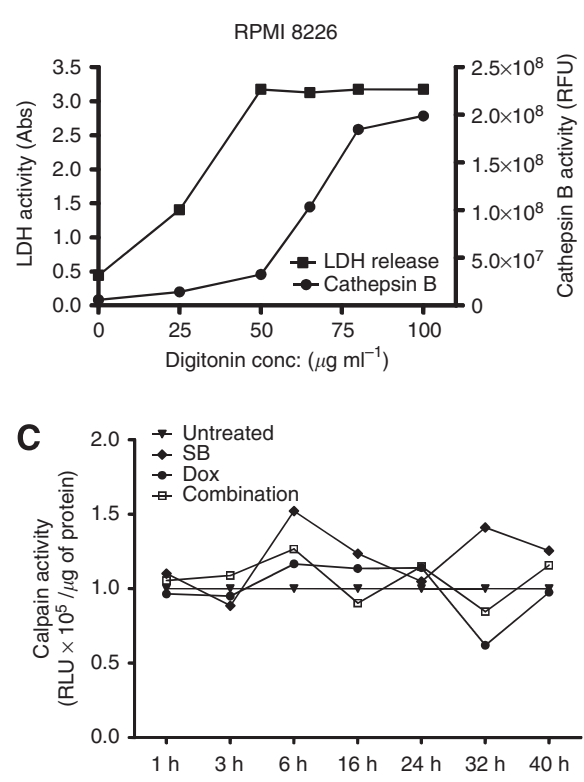

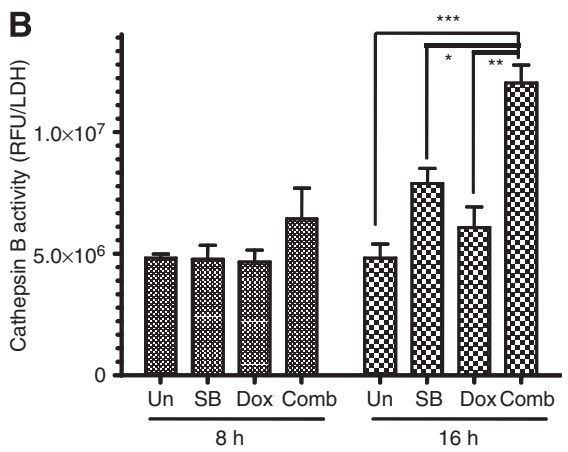

D

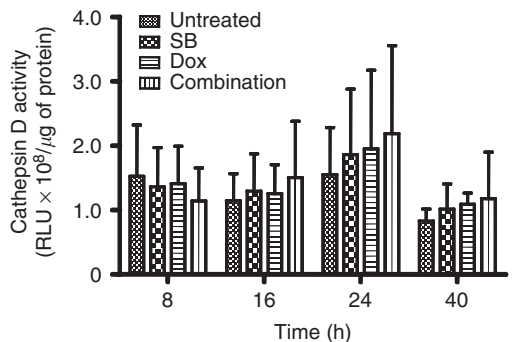

Figure 3 Combinations of butyrate and doxorubicin significantly increased the activity of cytoplasmic cathepsin B. (A) Optimisation of cytoplasmic cathepsin B extraction by permeabilisation of plasma membrane with digitonin. RPMl 8226 cells plasma membranes were permeabilised with increasing concentrations of digitonin for $10 \mathrm{~min}$ in ice. Permeabilisation of plasma membranes was monitored by assessing LDH activity (left $Y$ axis) and permeabilisation of lysosomes was monitored by cathepsin B activity (right $Y$ axis). Each point on the graph is mean \pm s.e.m. of two independent experiments. (B) Effects of butyrate and doxorubicin combination on the activity of cytoplasmic cathepsin B in myeloma cells. RPMI 8226 cells were treated with butyrate (SB, $600 \mu \mathrm{M}$ ), doxorubicin (Dox, $40 \mathrm{~nm}$ ) or their combination. Cells were harvested at indicated time periods, permeabilised with $50 \mu \mathrm{g} \mathrm{ml}^{-1}$ digitonin, and the activity of cathepsin B was measured using enzyme assay kits (Biovision Inc.). Cathepsin B activity was normalised to LDH activity; $* P<0.05$, ** $P<0.001$ and $* * * P<0.0001$. (C, D) Effects of butyrate and doxorubicin combination on the activity of calpain and cathepsin D in RPMI 8226 cells. Relative increase in total calpain $(\mathbf{C})$ and cathepsin $\mathrm{D}(\mathbf{D})$ activities were calculated by normalising to untreated samples. Each data point on the graph is mean \pm s.e.m. of two independent experiments performed in triplicate.

activity, information that might be useful for patient selection and for predicting treatment outcomes.

Histone deacetylase inhibitors have been identified as epigenetic modulators and are in clinical trials either as single agents or in combination (Marks and Xu, 2009; Richon et al, 2009). We have identified potentiation of apoptosis and marked reduction of the viability of both myeloma cell lines and fresh myeloma cells by combinations of HDACi (butyrate and SAHA) and doxorubicin (Figure 1, Table 1 and Supplementary Figure 2), which is in agreement with other studies (Marchion et al, 2004; Mitsiades et al, 2004; Catalano et al, 2006; Sanchez-Gonzalez et al, 2006; Sanchez et al, 2010). However, this study identified a prominent role for cathepsin B in mediating HDACi- and doxorubicin-potentiated apoptosis at their $\mathrm{IC}_{50}$ or sub-IC $\mathrm{I}_{50}$ concentrations. Interestingly, butyrate and doxorubicin potentiated apoptosis of myeloma cell lines, irrespective of p53 mutational status, and reduced the viability of fresh myeloma cells from patients who had been relapsed on a variety of therapies including liposomal doxorubicin (patient samples P02, P08, P15 and P16, Supplementary Table 1). These results suggested that HDACi and doxorubicin combinations could be useful for treating patients who recur on existing therapies and provide a rationale of testing this combination in clinics. In agreement with these results, in vitro and in vivo studies in mice have identified a synergistic antimyeloma effect for combinations of SAHA and the alkylating agents melphalan and doxorubicin (Campbell et al, 2010; Sanchez et al, 2010).

Lack of caspase 3 and 7 activation and the increased levels of nuclear AIF by butyrate and doxorubicin combination suggested the involvement of caspase-independent pathways in the potentiation of apoptosis in myeloma cells (Figure 2). Further investigation highlighted the importance of lysosomal cathepsin B in mediating apoptosis (Figures 3 and 4; Ivanova et al, 2008). Consistent with this, a cell permeable small-molecule inhibitor of cathepsin B or its downregulation with a siRNA rescued RPMI 8226 cells from potentiated apoptosis, suggesting a role for lysosomal cathepsin B in combination potentiated apoptosis (Figure 4).

A substantial reduction in apoptosis by a pan-caspase, but not caspase 3- and 7-specific inhibitor, suggests that potentiated apoptosis by HDACi and doxorubicin is a result of the concerted action of cathepsin B and caspases other than caspase 3 and 7 (Figure 2D and Supplementary Figure 3). Stresses acting on lysosomes could induce apoptosis by increasing the activity of cytoplasmic cathepsin B by various mechanisms, including (a) releasing the sequestered enzyme from lysosomes; (b) downregulating its negative regulators such as cystatin $\mathrm{A}$; or (c) increasing the expression of its co-activators (Ivanova et al, 2008). It is unclear which of the above processes led to the combination mediated increased activity of cathepsin B. Once activated, cathepsin B could induce the cleavage of Bid, a proapoptotic member of Bcl2 family (Bidere et al, 2003; Biswas et al, 2005; Droga-Mazovec et al, 2008). Activated Bid could depolarise mitochondria releasing either cytochrome $c$, resulting in caspase-dependent apoptosis, or AIF and Endo G, leading to caspaseindependent apoptosis (Boya et al, 2003). Increased cathepsin B activity in the cytoplasm also could lead to Bid-dependent or -independent activation of Bax by degrading its adaptor proteins, such as Ku70, Clusterin, Humanin and VDAC, that keep Bax in its 
A

RPMI 8226
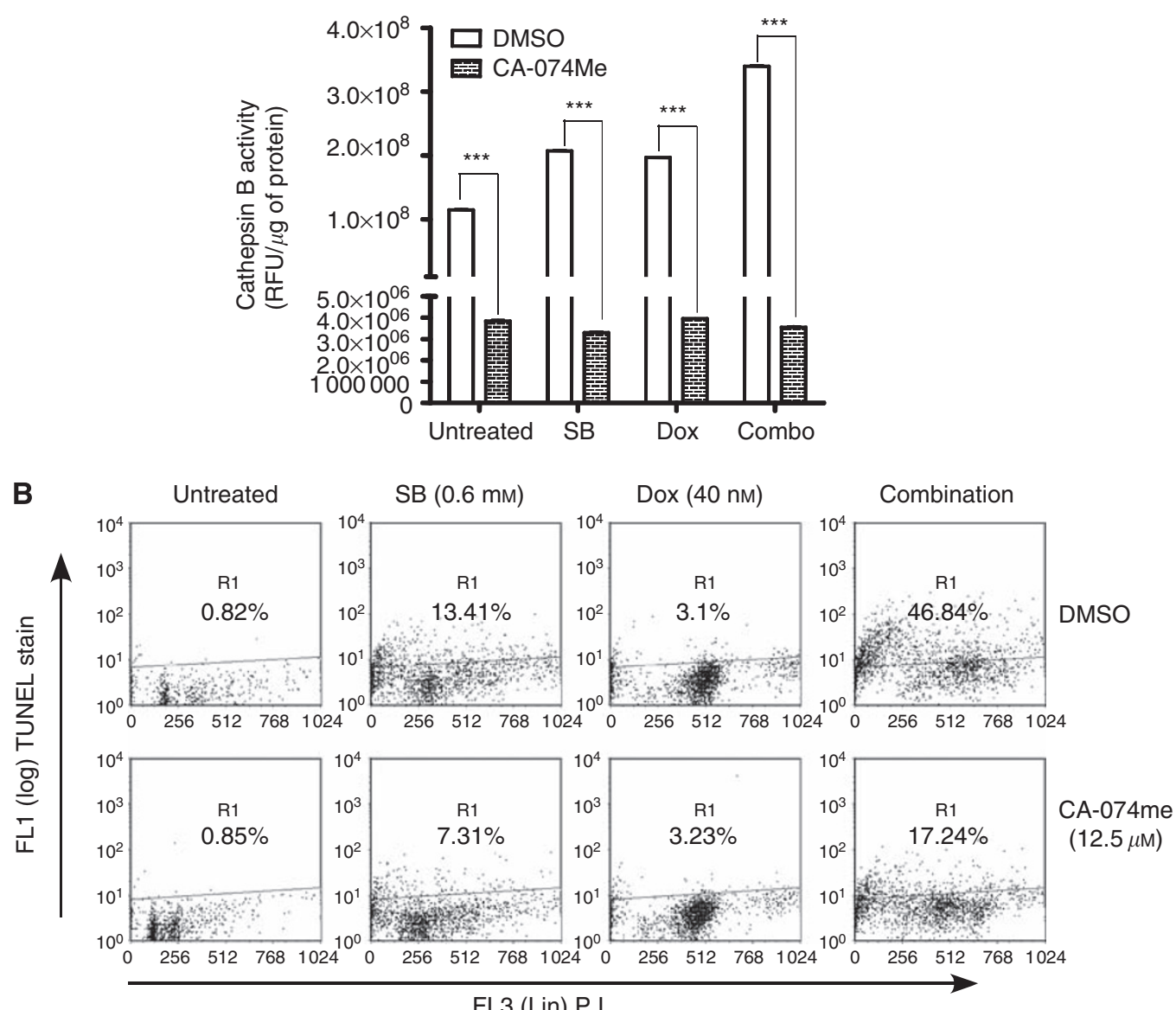

FL3 (Lin) P.I

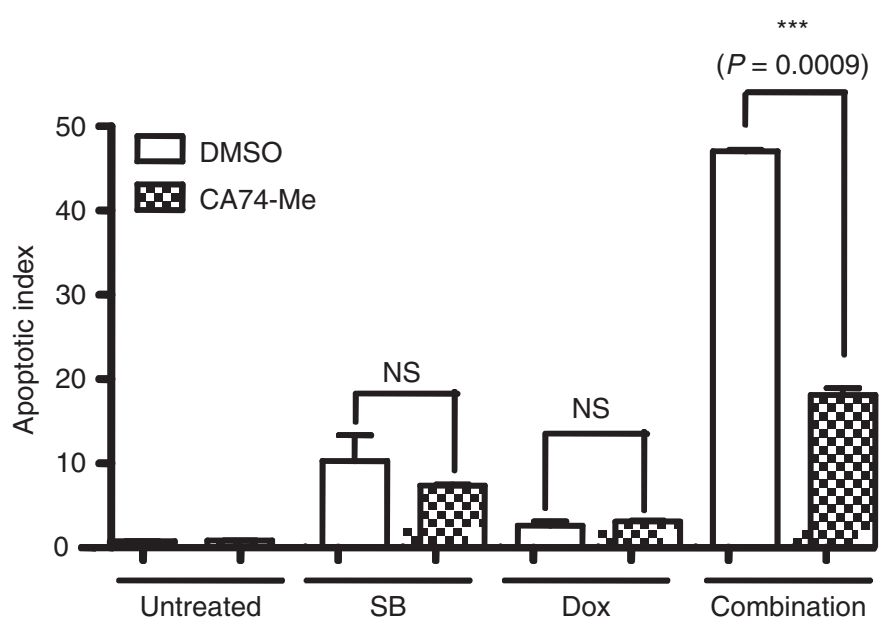

Figure 4 Cathepsin B inhibitor attenuated butyrate- and doxorubicin-induced apoptosis in RPMI 8226 cells. (A) Cathepsin B inhibitor attenuated butyrate- and doxorubicin-mediated activation of cathepsin B in RPMI 8226 cells. RPMI 8226 cells were treated with cell permeable cathepsin B-specific inhibitor CA-074Me (I $2.5 \mu \mathrm{M}$ ) or vehicle (DMSO) for I h before treatment with butyrate (SB; $0.6 \mathrm{~mm}$ ), doxorubicin (Dox; $40 \mathrm{nM}$ ) or combination. After $40 \mathrm{~h}$ treatment, cathepsin B activity was assessed using cathepsin B activity assay kit (Biovision Inc). Each data point on the graph is an average of two independent experiments performed in triplicate. (B) Cathepsin B inhibitor antagonised butyrate- and doxorubicin-induced apoptosis. After $72 \mathrm{~h}$ butyrate (SB; $0.6 \mathrm{~mm}$ ), doxorubicin (Dox; $40 \mathrm{nM}$ ) or combination treatment, apoptosis indices in vehicle (DMSO)- or CA-074me (I $2.5 \mu \mathrm{M}$ )-pretreated cells were compared with TUNEL assay. Scatter plot shown is one of two independent experiments with similar results, in which 10000 events were collected (top panel). Each bar on the graph is mean \pm s.e.m. of two independent experiments, and P-value of significantly different treatments is provided (bottom panel). (C, D) Downregulation of cathepsin B with a siRNA rescue RPMI 8226 cells from combination potentiated apoptosis. RPMI 8226 cells were transfected with either a scrambled siRNA (siControl) or a siRNA specific to cathepsin B (siCathepsin B). Knockdown of cathepsin B was determined by immunoblot analysis of $30 \mu \mathrm{g}$ of WHL $48 \mathrm{~h}$ post-transfection $(\mathbf{C})$ and apoptotic index $72 \mathrm{~h}$ post-transfection by TUNEL assay (D). Each bar on the graph is mean \pm s.e.m. of two independent experiments. 

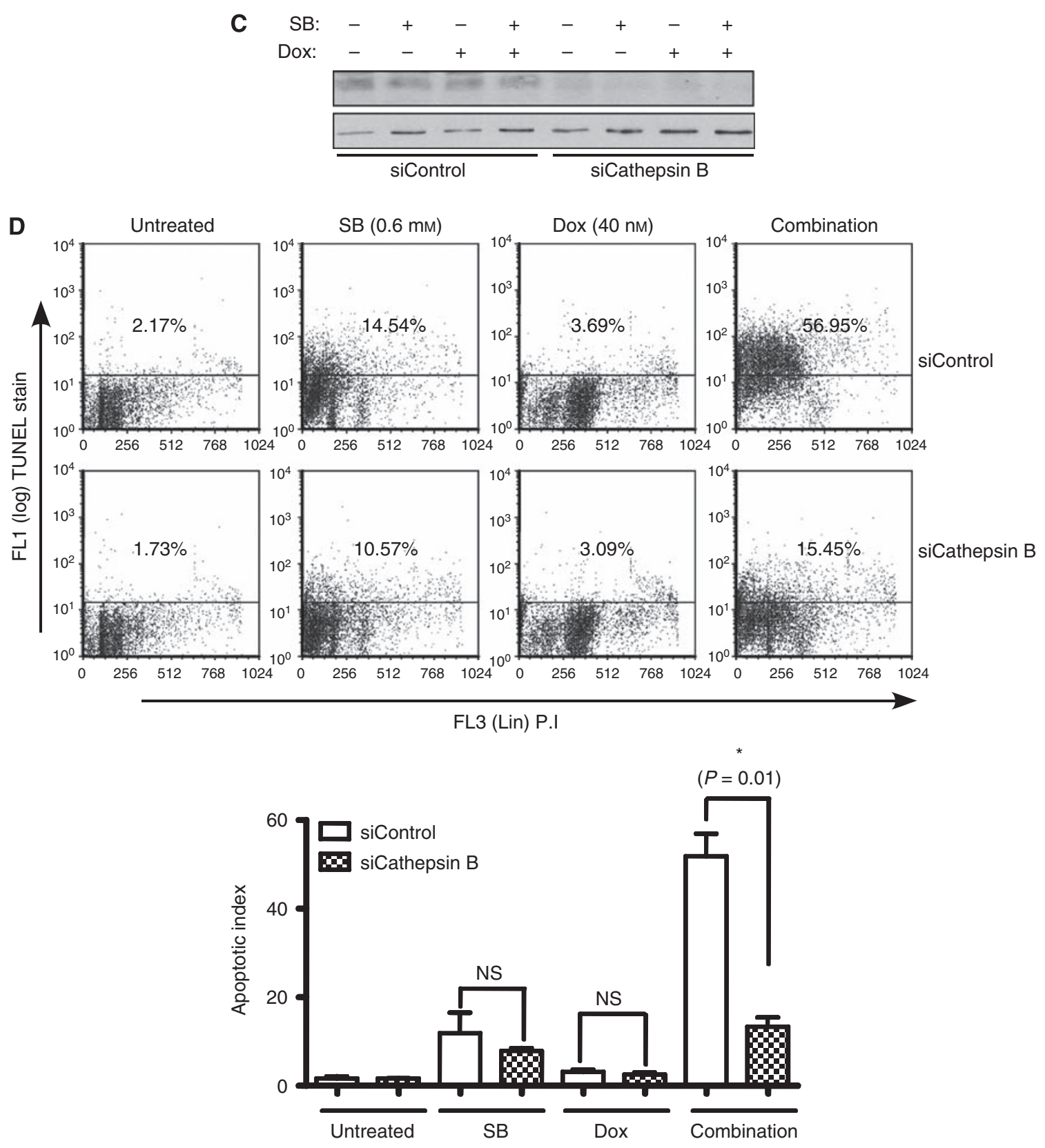

Figure 4 Continued.

inactive conformation (Guo et al, 2003; Zhang et al, 2005; Mazumder et al, 2007; Shoshan-Barmatz et al, 2008).

In summary, HDACi- and doxorubicin-potentiated apoptosis of myeloma cell lines was partly resulted in from activation of cathepsin B. Combination potentiated apoptosis and cathepsin B activity correlated with nuclear translocation of AIF, a mitochondrial sequestered proapoptotic factor involved in caspaseindependent cleavage of DNA (Bidere et al, 2003). Enhanced accessibility of DNA to doxorubicin through chromatin relaxation, prolonged nuclear retention of doxorubicin and induction of tumour suppressors have been implicated in HDACi-mediated potentiation of apoptosis by anthracyclins (Catalano et al, 2006; Pan et al, 2007; Hajji et al, 2008). However, results of the current investigation support an apoptosis model involving lysosomalmitochondrial crosstalk induced by the combinations of an epigenetic modulator and a DNA-damaging agent doxorubicin.

\section{ACKNOWLEDGEMENTS}

This study was partly supported by a Scott Hamilton CARES award to VC. We thank Dustin G Thomas and Perry J Evangelista for their excellent technical assistance; Merck \& Co. Inc. for providing SAHA (Vorinostat); Dr Rachid Baz, Janice Reed, RN, Kimberly Hamilton, $\mathrm{RN}$, and Beth Faiman, CNP for their help in procuring patient BM samples. We also thank Dr Alexandru Almasan and Barbara Jacobs of the Cleveland Clinic, Drs Jeffrey Yuan and Sans Rodriguez of Merck \& Co. Inc. for critical reading of the manuscript.

\section{Conflict of interest}

The authors declare no conflict of interest.

Supplementary Information accompanies the paper on British Journal of Cancer website (http://www.nature.com/bjc) 


\section{REFERENCES}

Badros A, Burger AM, Philip S, Niesvizky R, Kolla SS, Goloubeva O, Harris C, Zwiebel J, Wright JJ, Espinoza-Delgado I, Baer MR, Holleran JL, Egorin MJ, Grant S (2009) Phase I study of vorinostat in combination with bortezomib for relapsed and refractory multiple myeloma. Clin Cancer Res 15(16): 5250 - 5257

Bae SI, Cheriyath V, Jacobs BS, Reu FJ, Borden EC (2008) Reversal of methylation silencing of Apo2L/TRAIL receptor 1 (DR4) expression overcomes resistance of SK-MEL-3 and SK-MEL-28 melanoma cells to interferons (IFNs) or Apo2L/TRAIL. Oncogene 27(4): 490-498

Balliet RM, Chen G, Gallagher CJ, Dellinger RW, Sun D, Lazarus P (2009) Characterization of UGTs active against SAHA and association between SAHA glucuronidation activity phenotype with UGT genotype. Cancer Res 69(7): 2981-2989

Bergsagel PL, Kuehl WM (2001) Chromosome translocations in multiple myeloma. Oncogene 20(40): 5611-5622

Bidere N, Lorenzo HK, Carmona S, Laforge M, Harper F, Dumont C, Senik A (2003) Cathepsin D triggers Bax activation, resulting in selective apoptosisinducing factor (AIF) relocation in T lymphocytes entering the early commitment phase to apoptosis. J Biol Chem 278(33): 31401-31411

Biswas G, Guha M, Avadhani NG (2005) Mitochondria-to-nucleus stress signaling in mammalian cells: nature of nuclear gene targets, transcription regulation, and induced resistance to apoptosis. Gene 354: $132-139$

Boya P, Gonzalez-Polo RA, Poncet D, Andreau K, Vieira HL, Roumier T, Perfettini JL, Kroemer G (2003) Mitochondrial membrane permeabilization is a critical step of lysosome-initiated apoptosis induced by hydroxychloroquine. Oncogene 22(25): 3927-3936

Broker LE, Huisman C, Span SW, Rodriguez JA, Kruyt FA, Giaccone G (2004) Cathepsin B mediates caspase-independent cell death induced by microtubule stabilizing agents in non-small cell lung cancer cells. Cancer Res 64(1): $27-30$

Campbell RA, Sanchez E, Steinberg J, Shalitin D, Li ZW, Chen H, Berenson JR (2010) Vorinostat enhances the antimyeloma effects of melphalan and bortezomib. Eur J Haematol 84(3): 201-211

Carew JS, Nawrocki ST, Kahue CN, Zhang H, Yang C, Chung L, Houghton JA, Huang P, Giles FJ, Cleveland JL (2007) Targeting autophagy augments the anticancer activity of the histone deacetylase inhibitor SAHA to overcome Bcr-Abl-mediated drug resistance. Blood 110(1): $313-322$

Catalano MG, Fortunati N, Pugliese M, Poli R, Bosco O, Mastrocola R, Aragno M, Boccuzzi G (2006) Valproic acid, a histone deacetylase inhibitor, enhances sensitivity to doxorubicin in anaplastic thyroid cancer cells. J Endocrinol 191(2): 465-472

Chen CS, Wang YC, Yang HC, Huang PH, Kulp SK, Yang CC, Lu YS, Matsuyama S, Chen CY (2007) Histone deacetylase inhibitors sensitize prostate cancer cells to agents that produce DNA double-strand breaks by targeting Ku70 acetylation. Cancer Res 67(11): 5318-5327

Cheriyath V, Glaser KB, Waring JF, Baz R, Hussein MA, Borden EC (2007a) G1P3, an IFN-induced survival factor, antagonizes TRAIL-induced apoptosis in human myeloma cells. J Clin Invest 117(10): 3107-3117

Cheriyath V, Jacobs BS, Hussein MA (2007b) Proteasome inhibitors in the clinical setting: benefits and strategies to overcome multiple myeloma resistance to proteasome inhibitors. Drugs $R$ D 8(1): 1-12

Dai Y, Rahmani M, Dent P, Grant S (2005) Blockade of histone deacetylase inhibitor-induced RelA/p65 acetylation and NF-kappaB activation potentiates apoptosis in leukemia cells through a process mediated by oxidative damage, XIAP downregulation, and c-Jun N-terminal kinase 1 activation. Mol Cell Biol 25(13): 5429-5444

Droga-Mazovec G, Bojic L, Petelin A, Ivanova S, Romih R, Repnik U, Salvesen GS, Stoka V, Turk V, Turk B (2008) Cysteine cathepsins trigger caspase-dependent cell death through cleavage of bid and antiapoptotic Bcl-2 homologues. J Biol Chem 283(27): 19140 - 19150

Egger G, Liang G, Aparicio A, Jones PA (2004) Epigenetics in human disease and prospects for epigenetic therapy. Nature 429(6990): 457-463

Foghsgaard L, Lademann U, Wissing D, Poulsen B, Jaattela M (2002) Cathepsin B mediates tumor necrosis factor-induced arachidonic acid release in tumor cells. J Biol Chem 277(42): 39499-39506

Glaser KB (2007) HDAC inhibitors: clinical update and mechanism-based potential. Biochem Pharmacol 74(5): 659-671

Guo B, Zhai D, Cabezas E, Welsh K, Nouraini S, Satterthwait AC, Reed JC (2003) Humanin peptide suppresses apoptosis by interfering with Bax activation. Nature 423(6938): 456-461

Hajji N, Wallenborg K, Vlachos P, Nyman U, Hermanson O, Joseph B (2008) Combinatorial action of the HDAC inhibitor trichostatin A and etoposide induces caspase-mediated AIF-dependent apoptotic cell death in non-small cell lung carcinoma cells. Oncogene 27(22): $3134-3144$

He J, Tohyama Y, Yamamoto K, Kobayashi M, Shi Y, Takano T, Noda C, Tohyama $\mathrm{K}$, Yamamura $\mathrm{H}$ (2005a) Lysosome is a primary organelle in B cell receptor-mediated apoptosis: an indispensable role of Syk in lysosomal function. Genes Cells 10(1): $23-35$

Ivanova S, Repnik U, Bojic L, Petelin A, Turk V, Turk B (2008) Lysosomes in apoptosis. Methods Enzymol 442: 183-199

Laird PW (2005) Cancer epigenetics. Hum Mol Genet 14(Spec No 1): R65 - R76

Lincz LF, Yeh TX, Spencer A (2001) TRAIL-induced eradication of primary tumour cells from multiple myeloma patient bone marrows is not related to TRAIL receptor expression or prior chemotherapy. Leukemia 15(10): 1650 - 1657

Ludwig H, Beksac M, Blade J, Boccadoro M, Cavenagh J, Cavo M, Dimopoulos M, Drach J, Einsele H, Facon T, Goldschmidt H, Harousseau JL, Hess U, Ketterer N, Kropff M, Mendeleeva L, Morgan G, Palumbo A, Plesner T, San Miguel J, Shpilberg O, Sondergeld P, Sonneveld P, Zweegman S (2010) Current multiple myeloma treatment strategies with novel agents: a European perspective. Oncologist 15(1): 6-25

Luszczek W, Cheriyath V, Mekhail TM, Borden EC (2010) Combinations of DNA methyltransferase and histone deacetylase inhibitors induce DNA damage in small cell lung cancer cells: correlation of resistance with IFN-stimulated gene expression. Mol Cancer Ther 9(8): $2309-2321$

Mandic A, Viktorsson K, Strandberg L, Heiden T, Hansson J, Linder S, Shoshan MC (2002) Calpain-mediated Bid cleavage and calpainindependent Bak modulation: two separate pathways in cisplatininduced apoptosis. Mol Cell Biol 22(9): 3003-3013

Marchion DC, Bicaku E, Daud AI, Richon V, Sullivan DM, Munster PN (2004) Sequence-specific potentiation of topoisomerase II inhibitors by the histone deacetylase inhibitor suberoylanilide hydroxamic acid. J Cell Biochem 92(2): 223-237

Marks PA, Xu WS (2009) Histone deacetylase inhibitors: potential in cancer therapy. J Cell Biochem 107(4): 600-608

Mazumder S, Plesca D, Kinter M, Almasan A (2007) Interaction of a cyclin E fragment with Ku70 regulates Bax-mediated apoptosis. Mol Cell Biol 27(9): $3511-3520$

Mitsiades CS, Hayden PJ, Anderson KC, Richardson PG (2007) From the bench to the bedside: emerging new treatments in multiple myeloma Best Pract Res Clin Haematol 20(4): 797-816

Mitsiades CS, Mitsiades NS, McMullan CJ, Poulaki V, Shringarpure R, Hideshima T, Akiyama M, Chauhan D, Munshi N, Gu X, Bailey C, Joseph M, Libermann TA, Richon VM, Marks PA, Anderson KC (2004) Transcriptional signature of histone deacetylase inhibition in multiple myeloma: biological and clinical implications. Proc Natl Acad Sci USA 101(2): $540-545$

Mitsiades N, Mitsiades CS, Richardson PG, McMullan C, Poulaki V, Fanourakis G, Schlossman R, Chauhan D, Munshi NC, Hideshima T, Richon VM, Marks PA, Anderson KC (2003) Molecular sequelae of histone deacetylase inhibition in human malignant B cells. Blood 101(10): $4055-4062$

Moradei O, Vaisburg A, Martell RE (2008) Histone deacetylase inhibitors in cancer therapy: new compounds and clinical update of benzamide-type agents. Curr Top Med Chem 8(10): 841-858

Niesvizky R, Badros A (2010) Complications of multiple myeloma therapy, part2: risk reduction and management of venus thromboembolism, osteonecrosis of the jaw, renal complications, and anemia. J Natl Compr Canc Netw 8(Suppl 1): S13-S20

Ostenfeld MS, Fehrenbacher N, Hoyer-Hansen M, Thomsen C, Farkas T, Jaattela M (2005) Effective tumor cell death by sigma-2 receptor ligand siramesine involves lysosomal leakage and oxidative stress. Cancer Res 65(19): $8975-8983$

Pan L, Lu J, Wang X, Han L, Zhang Y, Han S, Huang B (2007) Histone deacetylase inhibitor trichostatin a potentiates doxorubicin-induced apoptosis by up-regulating PTEN expression. Cancer 109(8): 1676-1688

Paquet C, Sane AT, Beauchemin M, Bertrand R (2005) Caspase- and mitochondrial dysfunction-dependent mechanisms of lysosomal leakage and cathepsin B activation in DNA damage-induced apoptosis. Leukemia 19(5): $784-791$

Pei XY, Dai Y, Grant S (2004) Synergistic induction of oxidative injury and apoptosis in human multiple myeloma cells by the proteasome inhibitor 
bortezomib and histone deacetylase inhibitors. Clin Cancer Res 10(11): $3839-3852$

Richards T, Weber D (2010) Advances in treatment for relapses and refractory multiple myeloma. Med Oncol 27(Suppl 1): S25-S42

Richardson P, Mitsiades C, Colson K, Reilly E, McBride L, Chiao J, Sun L, Ricker J, Rizvi S, Oerth C, Atkins B, Fearen I, Anderson K, Siegel D (2008) Phase I trial of oral vorinostat (suberoylanilide hydroxamic acid, SAHA) in patients with advanced multiple myeloma. Leuk Lymphoma 49(3): $502-507$

Richardson PG, Mitsiades C, Schlossman R, Munshi N, Anderson K (2007) New drugs for myeloma. Oncologist 12(6): 664-689

Richon VM, Garcia-Vargas J, Hardwick JS (2009) Development of vorinostat: current applications and future perspectives for cancer therapy. Cancer Lett 280(2): $201-210$

Sanchez E, Shen J, Steinberg J, Li M, Wang C, Bonavida B, Chen H, Li ZW, Berenson JR (2010) The histone deacetylase inhibitor LBH589 enhances the anti-myeloma effects of chemotherapy in vitro and in vivo. Leuk Res; e-pub ahead of print 2010
Sanchez-Gonzalez B, Yang H, Bueso-Ramos C, Hoshino K, QuintasCardama A, Richon VM, Garcia-Manero G (2006) Antileukemia activity of the combination of an anthracycline with a histone deacetylase inhibitor. Blood 108(4): 1174-1182

Sandes E, Lodillinsky C, Cwirenbaum R, Arguelles C, Casabe A, Eijan AM (2007) Cathepsin B is involved in the apoptosis intrinsic pathway induced by Bacillus Calmette-Guerin in transitional cancer cell lines. Int J Mol Med 20(6): 823-828

Shoshan-Barmatz V, Keinan N, Zaid H (2008) Uncovering the role of VDAC in the regulation of cell life and death. J Bioenerg Biomembr 40(3): 183 - 191

Turk B, Stoka V (2007) Protease signalling in cell death: caspases versus cysteine cathepsins. FEBS Lett 581(15): $2761-2767$

Wang C, Jiang Z, Yao J, Wu X, Sun L, Liu C, Duan W, Yan M, Liu J, Zhang L (2008) Participation of cathepsin B in emodin-induced apoptosis in HK-2 Cells. Toxicol Lett 181(3): 196-204

Zhang H, Kim JK, Edwards CA, Xu Z, Taichman R, Wang CY (2005) Clusterin inhibits apoptosis by interacting with activated Bax. Nat Cell Biol 7(9): $909-915$ 